\title{
A cost minimization process of heat and energy consumption for direct dyeing of cotton fabric coloration with triethanolamine
}

\begin{abstract}
A cost minimization concept of heat and energy consumption for direct dyeing process of cotton fabric coloration was experimented with triethanolamine instead of sodium carbonate in the dyebath of direct dyeing with low temperature at $30^{\circ} \mathrm{C}$, medium temperature at $60^{\circ} \mathrm{C}$ and high temperature at $90^{\circ} \mathrm{C}$ and compared with the conventional method of direct dyeing with high temperature at $90^{\circ} \mathrm{C}$ where an acceptable range of increasing color strength $(\mathrm{K} / \mathrm{S})$ and color difference were observed for low temperature dyeing with triethanolamine (TEA method) comparing to the conventional dyeing process of high temperature with sodium carbonate (SC method). Considering heat and energy consumption in direct dyeing of cotton fabric coloration with triethanolamine method, the low temperature dyeing cost was minimized Rs. 2.24 comparing to high temperature sodium carbonate method dyeing cost.
\end{abstract}

Keywords: direct dyeing, cotton fabric, sodium carbonate, triethanolamine, color strength, cost minimization
Volume 5 Issue 5 - 2019

\author{
Anowar Hossain, ' AK Samanta ${ }^{2}$ \\ 'Department of Textile Engineering, City University, Savar, Dhaka, \\ Bangladesh \\ ${ }^{2}$ Department of Jute and Fibre Technology, University of \\ Calcutta, Kolkata, West Bengal, India
}

Correspondence: Md. Anowar Hossain, Lecturer, Department of Textile Engineering, City University, Savar, Dhaka, Bangladesh, Tel +880173268I I04, Email engr.anowar@yahoo.com

Received: September 18, 2019 | Published: September 26, 2019
Abbreviations: SC, sodium carbonate; TEA, triethanolamine; CE, capillary electrophoresis; TES, Triethanolamine-trisulphate; TLC, thin layer chromatography; VIS, electronic spectra; SEC, specific energy consumption; K/S, color strength

\section{Introduction}

Dyeing and finishing of textiles requires large amount of heat and energy, which cannot be eliminated but can be minimized with proper process selection, machine selection, dyes selection, auxiliaries selection as well as appropriate temperature selection in dyeing and finishing bath. In textile industry we often observe that huge amount of energy is consumed and wasted in the chemical processing of textiles. The question has been seriously vibrated regarding the need to save energy and heat which can be done by adding some specific chemicals in the reaction, so that the processes may be carried out at relatively lower temperature. The purpose of the room/reduced temperature dyeing and finishing to save energy and power which is an utmost importance to face the challenges of recent dyeing and finishing with competitive price. The fabric when exposed to lower temperature during chemical processing will definitely go through with less abrasion and breakages of fibres within it compared to those exposed at conventional higher temperature. The fabric chemically processed and finished at lower temperature might have the same colour, lustre and quality as compared to the one processed and finished at conventional higher temperatures.

Both sodium carbonate and triethanolamine are toxic for the aquatic life. Sodium carbonate is normally applied for direct dyeing application on cotton fabric for fixation of dyes on cotton fabric and Triehanolamine is popularly used for cosmetic and medicine production for bonding of different chemical.<smiles>[N+]#[N+]C(=O)[O-]</smiles>

Sodium Carbonate \& Triethanolamine

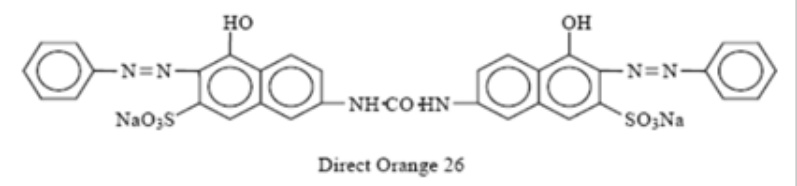

Malik SK, Bhaumik S, Mukherjee RN, ${ }^{1}$ studied that Lowtemperature dyeing of cotton by direct dyes. The feasibility of dyeing of cotton using three different direct dyes at low temperature in the presence of organic base triethanolamine (TEA) has been studied. It is observed that the extent of dyeing depends upon the temperature of dyeing. TEA concentration and dye concentration. This method gives dyeing comparable to that of the conventional method at relatively very low temperature $\left(50^{\circ}\right)$. The fastness properties of the samples dyed using TEA are also comparable with those of the samples dyed in conventional manner and the dyeing cost is considerably less. ${ }^{1}$

Lewis DM and Zhao $\mathrm{XF}^{2}$ found that Triethanolamine-trisulphate (TES) was synthesized in good yield. Capillary electrophoresis (CE) was used to monitor TES synthesis, to follow TES hydrolysis and to analyse the residual products formed during the application of TES to cellulosic fabrics. TES was found to react covalently with the cotton fibre when applied in the presence of sodium hydroxide. Cotton fabrics treated with alkaline TES solutions by a pad-cure route at elevated temperatures, subsequently gave high wrinkle recovery angles, confirming that cross-linking of the cellulose molecular chains had been achieved. Significant yellowing was observed following these treatments, but fabric whiteness was improved by adding a reducing agent to the system; however the latter addition gave a slight decrease in the wrinkle recovery values obtained from the treated cotton fabrics. ${ }^{2}$

Georgeta Maria SIMU $^{3}$ observed that the synthesis of a new symmetric disazo direct dye containing the non carcinogenic 4,40-diaminobenzanilide as the middle component and salicylic acid as the coupling component is presented. The synthesized dye is an analog of the benzidine based dye C. I. Direct Yellow 1 (C. I. 22,250) and was 
analyzed by thin layer chromatography (TLC), electronic spectra (VIS) andmass spectroscopy(FAB-MS). The coloristic and fastness properties of the synthesized dye were determined and compared with those of C. I. Direct Yellow 1. The toxicities of the dye and of its precursors were evaluated by biological tests, using the process of metamorphosis in the marine hydrozoon Hydractinia echinata. The concentrations (termed MRC50) at which the synthesized dye and its precursors antagonize metamorphosis induction were determined. ${ }^{3}$

Hans Rudolf Bolliger et al. ${ }^{4}$ were successfully applied Direct dyes on cellulosic material with triethanolamine.

Lenore \& Anne Wilcock ${ }^{5}$ investigated that direct dyes containing more than one amino or amido group in their structure were found most likely to achieve relatively good nep coverage. Scanning electron micrographs revealed considerable variation in the types of fibres making up the individual neps in a single piece of cotton fabric. Differences in direct dye behaviour towards nep coverage were most evident with those neps composed of immature fibres with some secondary wall development.

Palamutcu $\mathrm{S}^{6}$ studied that Electric energy is one of the primary energy sources consumpted in cotton textile processing. Current energy cost rate is reported about $8 \mathrm{e} 10 \%$ in the total production cost of an ordinary textile product manufactured in Turkey. Significantly important share of this energy cost is electric energy. The aim of this paper was to investigate unit electric energy consumption of cotton textile processing stages using real-time measurements method. Actual and estimated Specific Energy Consumption (SEC) values for electric energy was calculated in the cotton textile processing stages of spinning, warping, sizing, weaving, wet processing and clothing manufacturing. Actual electric energy consumption data are gathered from monthly records of the involved plant managements. Estimated electric energy consumption data is gathered through onsite measurement. Actual and estimated electric energy consumption data and monthly production quantities of the corresponding months are used to facilitate specific electric energy consumption of the plants. It is found that actual electric energy consumption amount per unit textile product is higher than the estimated electric energy consumption amount per unit textile product of each involved textile processing stages. $^{6}$

Electric energy is one of the most commonly used energy types in the textile and clothing plants, used to supply energy for textile machinery, heating and cooling control systems, lighting, and office equipments. It is estimated from the report of $\mathrm{UNIDO}^{7}$ that electricity consumption rate in the total consumpted energy for individual textile production stages are $93 \%$ for spinning, $85 \%$ for weaving, $43 \%$ for wet processing, and $65 \%$ for clothing manufacturing. Rest of the energy that is used in the textile processing plants is supplied by other energy sources of fuel, natural gas, and coal. ${ }^{8,9}$

Sizing process is an important process between spinning and weaving processes. Sizing of yarns before warping mostly requires indirect steam that is heated using electricity, gas or oil. Weaving processes requires electrical energy. Amount of energy consumption changes depending on fabric structure and technical parameters of weaving machine. Controlled climatic room condition (25 C temperatures, $65 \%$ relative humidity) in spinning and weaving rooms is another important electric energy consuming station in textile processing stages. Seasonal climatic variation is also important parameter for energy consumption quantity of air conditioning systems. ${ }^{10}$
Wet processing stages of pretreatment, bleaching, dyeing, post treatments and drying-fixation processes consume considerable amounts of heat in the form of hot water, steam and hot air. Mechanical parts of the wet processing machinery are driven using electric energy. Total electric energy consumption in wet processing is quite low comparing the other textile processing stages. Clothing manufacturing stages of laying up, cutting, sewing, cleaning with air suction, ironing, and transporting processes mostly consumes electric energy. Only heating, ironing processes may require steam or hot air. Research about energy management, improvement of energy efficiency, and energy saving potentials are main concern of many different industrial sectors including textile sector. ${ }^{11-26}$

There have been many international ${ }^{711-13,27-31}$ projects concerning energy management and improvement of energy efficiency in different industrial sectors. Energy management methods and practices are described using the total quality management approach of P (plan), D (do), C (check) and A (action) cycles. ${ }^{7,28-30,32-34}$

Bhattacharyya N \& Shalini chouhan ${ }^{35}$ noted an attempt has been made to investigate the interaction of four direct dyes possessing varying number of solubilizing groups with four commonly used dye fixing agents of amine formaldehyde condensale type of product in aqueous solution there studies will help to evaluate different types of dye fixing agents for obtaining better wash and perspiration fastness of the dyed samples. The results indicate that the interaction depends on the nature, concentration and functional groups of dye fixing agents. Also the sulphonate and other groups present in the dye molecules such as $-\mathrm{OH},-\mathrm{NH} 2,-\mathrm{COO}$ - also contribute to the interaction with dye fixing agents. ${ }^{35}$

Bolliger et al. ${ }^{36}$ experimented that a process for the production of stable concentrated solutions of water soluble tertiary ammonium salts of direct dyes, substantially free of inorganic salts is described by condensing in aquous medium two mols of tertiary ammonium salts of identical or dissimilar azo and/or carboxylic acid compounds containing at least one primary or secondary amino group with one mol of a polyfunctional acylating agent in the presence of at least two mols of a tertiary amine with or without the addition of further auxiliary products.

Materials used: Scoured and bleached 130 GSM, S/J knitted cotton fabric was applied for this experiment and Atul direct orange 26, laboratory grade salt, sodium carbonate and triethanolamine (TEA) were used for dyeing.

\section{Methodology}

Scoured and bleached S/J cotton fabric was dyed with $1 \%$ direct dye, orange- 26 in twelve different formulation with $0 \%, 1 \%, 2 \%$ and $3 \%$ concentration of triethanolamine for the newly proposed method of triethanolamine method as well as standard direct dyeing process of conventional method was trialed with the formulation of $20 \%$ sodium carbonate and compared with the process of direct dyeing with triethanolamine method where no sodium carbonate was applied and a fixed recipe of direct dye, common salt were used by keeping the same time of dye exhaustion with three selected temperatures lower $30^{\circ} \mathrm{C}$-medium $60^{\circ} \mathrm{C}$-high $90^{\circ} \mathrm{C}$. Thus the same materials and liquor ratio: 1:20 was maintained for all dye bath and the observation was trialled for using triehanolamine instead of sodium carbonate in the dyebath of direct dyeing. Dyed fabric was tested after soaping and washing (Table 1) 
Table I Experimentation for Comparison of dyeing performance between sodium carbonate and tri ethanolamine for the application of direct dyes on cotton fabric in different formulation at $90^{\circ} \mathrm{C}, 60^{\circ} \mathrm{C}, 30^{\circ} \mathrm{C}$

\begin{tabular}{|c|c|c|}
\hline Formulation: 0 I & Formulation: 0 I & Formulation: 0 I \\
\hline Direct Dye: I\% & Direct Dye: I\% & Direct Dye: I\% \\
\hline Common Salt: $20 \%$ & Common Salt: $20 \%$ & Common Salt: $20 \%$ \\
\hline Sodium Carbonate: $20 \%$ & Sodium Carbonate: $20 \%$ & Sodium Carbonate: $20 \%$ \\
\hline Tri ethanol amine: $0 \%$ & Tri ethanol amine: $0 \%$ & Tri ethanol amine: $0 \%$ \\
\hline Temperature: $90^{\circ} \mathrm{C}$ & Temperature: $60^{\circ} \mathrm{C}$ & Temperature: $30^{\circ} \mathrm{C}$ \\
\hline Time: 40 minute & Time: 40 minute & Time: 40 minute \\
\hline Formulation: 02 & Formulation: 02 & Formulation: 02 \\
\hline Direct Dye: I\% & Direct Dye: I\% & Direct Dye: I\% \\
\hline Common Salt: $20 \%$ & Common Salt: $20 \%$ & Common Salt: $20 \%$ \\
\hline Sodium Carbonate: $0 \%$ & Sodium Carbonate: $0 \%$ & Sodium Carbonate: $0 \%$ \\
\hline Tri ethanol amine: $1 \%$ & Tri ethanol amine: I\% & Tri ethanol amine: I\% \\
\hline Temperature: $90^{\circ} \mathrm{C}$ & Temperature: $60^{\circ} \mathrm{C}$ & Temperature: $30^{\circ} \mathrm{C}$ \\
\hline Time: 40 minute & Time: 40 minute & Time: 40 minute \\
\hline Formulation: 03 & Formulation: 03 & Formulation: 03 \\
\hline Direct Dye: I\% & Direct Dye: I\% & Direct Dye: I\% \\
\hline Common Salt: $20 \%$ & Common Salt: $20 \%$ & Common Salt: $20 \%$ \\
\hline Sodium Carbonate: $0 \%$ & Sodium Carbonate: $0 \%$ & Sodium Carbonate: $0 \%$ \\
\hline Tri ethanol amine: $2 \%$ & Tri ethanol amine: $2 \%$ & Tri ethanol amine: $2 \%$ \\
\hline Temperature: $90^{\circ} \mathrm{C}$ & Temperature: $60^{\circ} \mathrm{C}$ & Temperature: $30^{\circ} \mathrm{C}$ \\
\hline Time: 40 minute & Time: 40 minute & Time: 40 minute \\
\hline Formulation: 04 & Formulation: 04 & Formulation: 04 \\
\hline Direct Dye: I\% & Direct Dye: I\% & Direct Dye: I\% \\
\hline Common Salt: $20 \%$ & Common Salt: $20 \%$ & Common Salt: $20 \%$ \\
\hline Sodium Carbonate: $0 \%$ & Sodium Carbonate: $0 \%$ & Sodium Carbonate: $0 \%$ \\
\hline Tri ethanol amine: $3 \%$ & Tri ethanol amine: $3 \%$ & Tri ethanol amine: $3 \%$ \\
\hline Temperature: $90^{\circ} \mathrm{C}$ & Temperature: $60^{\circ} \mathrm{C}$ & Temperature: $30^{\circ} \mathrm{C}$ \\
\hline Time: 40 minute & Time: 40 minute & Time: 40 minute \\
\hline
\end{tabular}

Measurement of color strength $(\mathbf{K} / \mathbf{S}): \mathrm{K} / \mathrm{S}$ value was measured for analysis of surface colour strength of the dyed cotton fabric samples. K/S values of dyed cotton fabrics were determined by measuring surface reflectance of the dyed samples using computer aided Macbeth 2020 plus reflectance spectrophotometer followed by calculating the K/S using following Kulbeka-Munk equation with the help of relevant software.

\section{$\mathrm{K} / \mathrm{S}=(1-\mathrm{R} \lambda \max )^{2} / 2 \mathrm{R} \lambda \max$}

Where, $\mathrm{K}$ is the co-efficient of absorption, $\mathrm{S}$ is the co-efficient of scattering and $\mathrm{R} \lambda \max$ is the reflectance value at maximum absorbance wave length $\mathrm{R} \lambda \max$.

The color fastness to washing was evaluated as per the ISO2 and the color fastness to light be observed by sunlight and visual observation process.

\section{Result and discussion}

In Table 2 and Figure $1 \&$ Figure 2 showed that Direct dyeing with low temperature at $30^{\circ} \mathrm{C}$, medium temperature at $60^{\circ} \mathrm{C}$ and high temperature at $90^{\circ} \mathrm{C}$ and compared with the conventional method of direct dyeing with high temperature at $90^{\circ} \mathrm{C}$ where an acceptable range of increasing color strength $(\mathrm{K} / \mathrm{S})$ and color difference were observed for low temperature dyeing with triethanolamine comparing to the conventional dyeing process for high temperature dyeing process with sodium carbonate. In Table 3 and Table 4 \& Figure 3 showed that considering heat and energy consumption in direct dyeing of cotton fabric coloration with triethanolamine method, the low temperature dyeing cost was minimized Rs. 2.24 comparing to high temperature sodium carbonate method dyeing cost. 
Table 2 Comparison of dyeing properties of low temperature dyeing as well as conventional high temperature dyeing of cotton fabric using TEA as the low temperature dyeing assistant on Surface colour Strength $(\mathrm{K} / \mathrm{S})$ at different TEA concentrations

\begin{tabular}{|c|c|c|}
\hline Sample types & K/S Value & $\Delta \mathbf{E}$ \\
\hline Bleached fabric & 0.4 & \\
\hline Formulation- $1,90^{\circ} \mathrm{C}, 0 \%$ TEA with SC & 4 & 8.46 \\
\hline Formulation-2, $90^{\circ} \mathrm{C}, \mathrm{I} \%$ TEA & 4.08 & 8.44 \\
\hline Formulation- $3,90^{\circ} \mathrm{C}, 2 \%$ TEA & 4.1 & 8.43 \\
\hline Formulation- $4,90^{\circ} \mathrm{C}, 3 \%$ TEA & 4.12 & 8.4 \\
\hline Formulation- $5,60^{\circ} \mathrm{C}, 0 \%$ TEA with SC & 3.8 & 8.58 \\
\hline Formulation- $6,60^{\circ} \mathrm{C}, 1 \%$ TEA & 3.83 & 8.56 \\
\hline Formulation-7, $60^{\circ} \mathrm{C}, 2 \%$ TEA & 3.85 & 8.53 \\
\hline Formulation- $8,60^{\circ} \mathrm{C}, 3 \%$ TEA & 3.89 & 8.52 \\
\hline Formulation- $9,30^{\circ} \mathrm{C}, 0 \%$ TEA with SC & 3.5 & 8.69 \\
\hline Formulation- $10,30^{\circ} \mathrm{C}, 1 \%$ TEA & 3.53 & 8.6 \\
\hline Formulation-I I, $30^{\circ} \mathrm{C}, 2 \%$ TEA & 3.55 & 8.61 \\
\hline Formulation- $12,30^{\circ} \mathrm{C}, 3 \%$ TEA & 3.58 & 8.59 \\
\hline
\end{tabular}

$\Delta \mathrm{E}$, total colour difference, $\mathrm{SC}$, sodium carbonate, $\mathrm{TEA}$, triethanol amine, $\mathrm{K} / \mathrm{S}$, surface colour strength

Table 3 Cost of high temperature dyeing method with conventional process at $90^{\circ} \mathrm{C}$

\begin{tabular}{llll}
\hline Items & Total amount & Rate (Rs/Kg or Litre) & Cost (Rs/Kg of goods) \\
\hline TEA & 0 & 72 & 0 \\
Steam in raising water temperature & $2.96 \mathrm{Kg}$ & 0.6 & 1.78 \\
Steam loss during temperature raising & $0.18 \mathrm{Kg}$ & 0.6 & 0.11 \\
Steam loss during hold time & $0.46 \mathrm{Kg}$ & 0.6 & 0.28 \\
& & Total & 2.96 \\
\hline
\end{tabular}

Table 4 Cost of low temperature dyeing method with triethanolamine method at $30^{\circ} \mathrm{C}$

\begin{tabular}{llll}
\hline Items & Total amount & Rate (Rs/Kg or Litre) & Cost (Rs/Kg of goods) \\
\hline TEA & 0.0 I0Litre & 72 & 0.72 \\
Steam in rising water temperature & 0 & 0 & 0 \\
Steam loss during temperature & 0 & 0 & 0 \\
Steam loss during hold time & 0 & 0 & 0 \\
\end{tabular}

Citation: Hossain A, Samanta AK.A cost minimization process of heat and energy consumption for direct dyeing of cotton fabric coloration with triethanolamine.J Textile Eng Fashion Technol. 2019;5(5):235-240. DOI: 10.15406/jteft.2019.05.00207

Figure 2 Comparisom of color differences $(\Delta \mathrm{E})$ between sodium carbonate and tri ethanol amine for the application of direct dyes on cotton fabric in different formulation at $90^{\circ} \mathrm{C}, 60^{\circ} \mathrm{C}, 30^{\circ} \mathrm{C}$.

[TEA-Triethanol Amine]

Figure I Comparison of color strength (K/S value) between sodium fabric in different formulation at $90^{\circ} \mathrm{C}, 60^{\circ} \mathrm{C}, 30^{\circ} \mathrm{C}$.

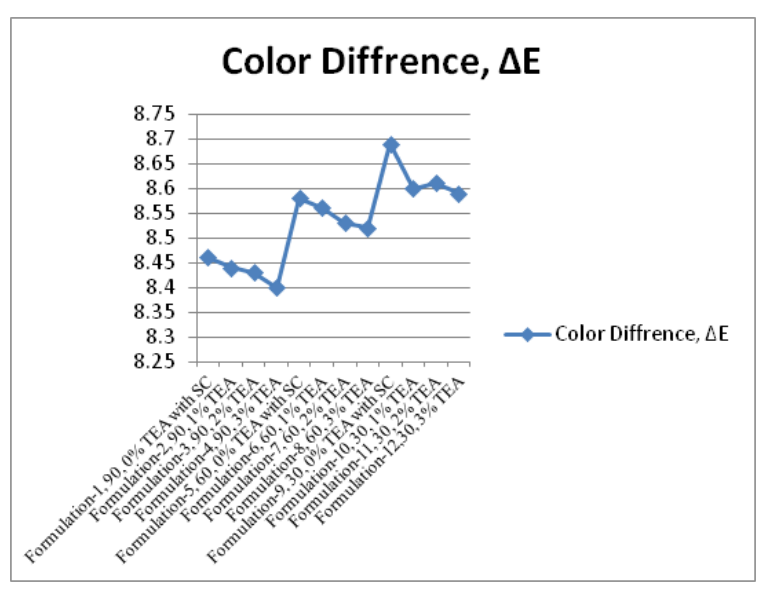




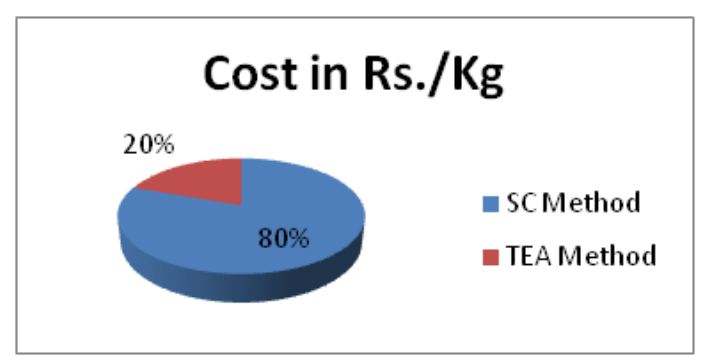

Figure 3 Cost comparison between high temperature direct dyeing with sodium carbonate at $90^{\circ} \mathrm{C}$ (SC Method) and low temperature direct dyeing at $30^{\circ} \mathrm{C}$ with triethanolamine (TEA Method).

\section{Effect of triethanolamine}

Direct dyeing on cotton fabric observed that the dyeing with TEA gives better colour yield at low temperature comparing to conventional method.

\section{Effect of dyeing temperature}

The $\mathrm{K} / \mathrm{S}$ values show that the colour yield at $60^{\circ} \mathrm{C}$ is highest with TEA, even almost nearest that in conventional method, but the increase in $\mathrm{K} / \mathrm{S}$ with the increase in dyeing temperature from $30^{\circ} \mathrm{C}$ to $60^{\circ} \mathrm{C}$ was slightly increased in dye fixation for triethanolamine method. The increase in colour strength with the increase in temperature in case of dyeing with TEA appears to be due to the following reasons: (1) opening up the cellulose structure (2) increasing the accessibility of cellulose structure and (3) overcoming the activation energy barrier of the dyeing process, thereby increasing the level of molecular activity of the dye-fibre system as well as dye-fibre interaction.

\section{Effect of TEA instead of sodium carbonate}

A neligible variation of K/S value was marked for both processes of sodium carbonate and triethanolamine which may elucidate that the exhaustion of dyes into the fabric is possible by lower temperature TEA due to having dye-fibre interactions in dyebath.

The $\Delta \mathrm{E}$ value showed almost nearest for both process of sodium carbonate and triethanolamine which may clarify that the adsorption of dyes on the fabric surface is not influenced by lower temperature TEA due to having little dye aggregation.

Fastness properties: The color fastness to wash and color fastness to light (sunlight) was found negligible difference for low temperature dyeing comparing to high temperature dyeing in conventional method.

Cost comparison of low temperature and high temperature method: Cost of steam production for dyeing machine is Rs. $0.60 / \mathrm{Kg}$ and cost of Triethanolamine is Rs. 72 Litre/Kg. ${ }^{1}$

\section{From the calculated value of table-3 \& 4}

a. Cost of high temperature dyeing method with conventional process at $90^{\circ} \mathrm{C}=$ Rs. 2.96

b. Cost of low temperature dyeing method with triethanolamine method at $30^{\circ} \mathrm{C}=$ Rs. 0.72

\section{Proposed reaction in dye bath}

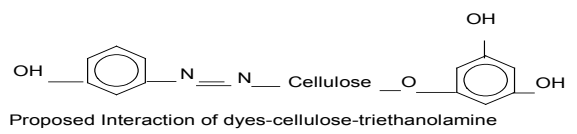

The interection between dye and fibre depends not only the chromophore group of dyes i.e sulphonic acid group of dyes used in this experiment, but the structure of dye fixing agent is a very critical matter of color variation on the surface of fabric may be expected from this experiment of cotton fabric coloration which may be stated as Dye-Fibre-Triethanolamine.

\section{Conclusion}

Direct dyes at different concentration of TEA, it has been observed that the $\mathrm{K} / \mathrm{S}$ values are almost same and does not show much difference when it is done in $30^{\circ} \mathrm{C}$ and at $60^{\circ} \mathrm{C}$ when compared to $90^{\circ} \mathrm{C}$. Thus, it has been proved that using TEA at room temperature shows similar results as $90^{\circ} \mathrm{C}$ in the conventional method of direct dyeing. So using TEA with Direct dyes at low temperature more energy and power can be saved and thus huge amount of cost can be minimized.

\section{Acknowledgments}

None.

\section{Funding}

None.

\section{Conflicts of interest}

The authors declare that they have no competing interests.

\section{References}

1. Malik SK, Bhaumik S, Mukherjee RN. Low temperature dyeing of cotton by direct dyes. Indian Jornal of Fibre and Textile Research. 2003;28(4):462-465.

2. Lewis DM, Zhao XF. Synthesis of triethanolamine-trisulphate and its application to cellulosic fabrics. Coloration Technology. 2004;120(4):172-179.

3. Georgeta MariaSIMU, SergiuAdrianCHICU,NicoleMORIN, etal.Direct dyes derived from 4,40diaminobenzanilidesynthesis,characterization and toxicity evaluation of a disazo symmetric direct dye. Turkish Journal of Chemistry. 2004;28:579-585.

4. Hans Rudolf Bolliger. Stable concentrated solution of direct dyeing and process for their manufacture. The chemical technology of dyeing and printing.

5. Lenore C, Wilcock A. Relationship between direct dye characteristics and coverage of immature fibre neps in dyed cotton fabric. Coloration Technology. 1988;104(12):477-482.

6. Palamutcu S. Electric energy consumption in the cotton textile processing stages. Energy. 2010;35(7):2945-2952.

7. UNIDO. Textile industry. Output of a seminar on energy conservation in textile industry. United Nations Industrial Development Organization; 1992.

8. Palanichamy C, Sundar Babu N. Second stage energy conservation experience with a textile industry. Energy Policy. 2005;33(5):603-609.

9. Ozturk HK. Energy usage and cost in the textile industry: a case study for Turkey. Energy. 2005;30(13):2424-2446.

10. Öngüt ÇE. Turkish textile and clothing industry's adaptation to the changing competitive. Report of state planning organization; 2007.

11. Hall DM. Energy and water savings in the textile industry. Journal of Industrial Textiles. 2002;31(4):235-253.

12. Chang L, Tang ZX, Wang X. Effect of yarn hairiness on energy consumption in rotating a ring-spun yarn package. Textile Research Journal. 2003;73(11):949-954. 
13. Yang M, Rumsey P. Energy conservation in typical Asian countries. Energy Sources, Part A: Recovery, Utilization, and Environmental Effects. 1997;19(5):507-521.

14. Hepbasli A, Ozalp N. Development of energy efficiency and management implementation in the Turkish industrial sector. Energy Conversionand Management. 2003;44:231-249.

15. Visvanathan C, Kumar S, Priambodo A, et al. Energy and environmental indicators in the Thai textile industry.

16. Saidur R, Rahim NA, Masjuki HH, et al. Enduse energy analysis in the Malaysian industrial sector. Energy. 2009;34(2):153-158.

17. Sharma GP, Pradas S. Specific energy consumption in microwave drying of garlic cloves. Energy. 2006;31(12):1921-1926.

18. Ramirez CA, Patel M, Blok K. From fluid milk to milk powder: energy use and energy efficiency in the European dairy industry. Energy. 2006;31(12):1984-2004.

19. Ramirez CA, Patel M, Blok K. How much energy to process one pound of meat? A comparison of energy use and specific energy consumption in the meat industry of four European countries. Energy. 2006;31(12):2047-2063.

20. Xu T, Flapper J, Kramer KJ. Characterization of energy use and performance of global cheese processing. Energy. 2009;34(11):19932000

21. Persson $\mathrm{J}$, Berntsson T. Influence of seasonal variations on energysaving opportunities in a pulp mill. Energy. 2009;34(10):1705-1714.

22. Waheed MA, Jekayinfa SO, Ojediran JO, et al. Energetic analysis of fruit juice processing operations in Nigeria. Energy. 2008;33(1):35-45.

23. Hasanbeigi A, Menke C, du Pont P. Barriers to energy efficiency improvement and decision-making behavior in Thai industry. Energy Efficiency. 2010;3(1):33-52.

24. Nagesha N. Role of energy efficiency in sustainable development of smallscale industry clusters: an empirical study. Energy for Sustainable Development. 2008;12(3):34-39.
25. Purohit S. Energy conservation in textile industry. Textile Magazine; 2007.

26. Chan DY-L, Yang K-H, Hsu C-H, et al. Current situation of energy conservation in high energy-consuming industries in Taiwan. Energy Policy. 2007;35(1):202-209.

27. Kavak K. Investigation of energy efficiency in the world and Turkey and the Turkish Industry in energy efficiency. Energy consumption in Turkish industry; 2005.

28. Shinkawa N. An outlook for energy in energy conservation point of view. Kitakyushu, Japan: Kyushu International Center, JICA and KITA; 1998.

29. Capehart BL, Turner WC, Kennedy WJ. Guide to energy management. 5th ed. International Version; 2007.

30. Energy Management Manual. EC European Intelligent Energy Program EMS. Textile Project; 2006.

31. Visvanathan C, Kumar S, Shi Han. Cleaner production in textile sector: Asian scenario. Thailand: Asian Institute of Technology; 2000.

32. Official Bulletin. Regulation on the measures to be taken for increasing efficiency in the energy consumption of industrial establishments. Ankara, Turkey: Ministry of Energy and Natural Sources; 1995.

33. EIE (Electricity Research Organization). Energy management principle for industry. 2nd ed. Ankara, Turkey: General Directorate of Electrical Works Etud Administration, National Energy Saving Center; 2004.

34. Hepbasli A, Ozalp N. Development of energy efficiency and managemen implementation in the Turkish industrial sector. Energy Conversion and Management. 2003;44(2):231-249.

35. Bhattacharyya $\mathrm{N}$, Shalini chouhan. Interaction of direct dyes with cationic dye fixing ayents. Indian Journal of Fibre and Textile Research. 1991;16:140-145.

36. Bolliger. Stable concentrated solutions of direct dyes and process for their manufacture. United State patent, Patent No: 3,852,029; 1974. 